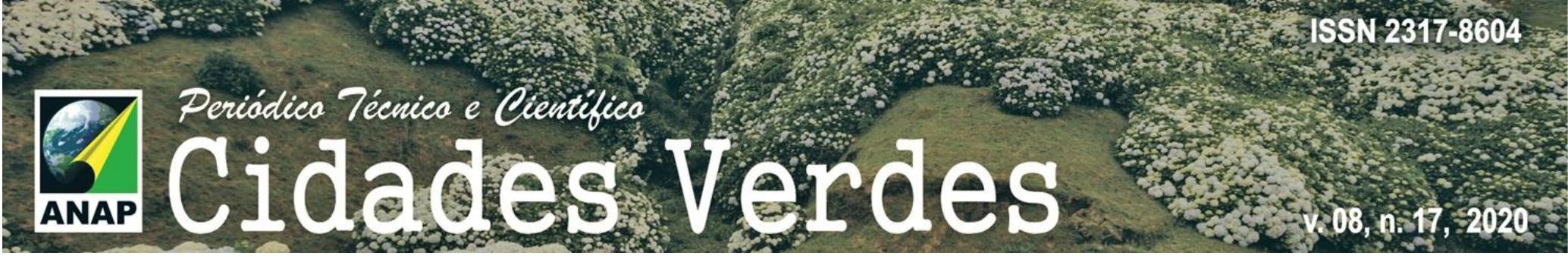

\title{
Compostagem de resíduos sólidos orgânicos em Florianópolis-SC: um caminho sustentável
}

Compostation of organic solid waste in Florianópolis-SC:

a sustainable way

Compostación de residuos sólidos orgánicos en Florianópolis-SC:

una forma sostenible

Aline Daniela Sauer

Discente do curso Licenciatura em Educação do Campo e Mestranda em Psicologia Social e Cultura, UFSC, Brasil alidsauer@hotmail.com

Magdielly Kedma Taborda de Lima

Discente do curso Licenciatura em Educação do Campo, UFSC, Brasil magdiellykedma65@gmail.com

Thaise Costa Guzzatti

Professora Doutora, UFSC, Brasil thaise.acolhida@gmail.com 


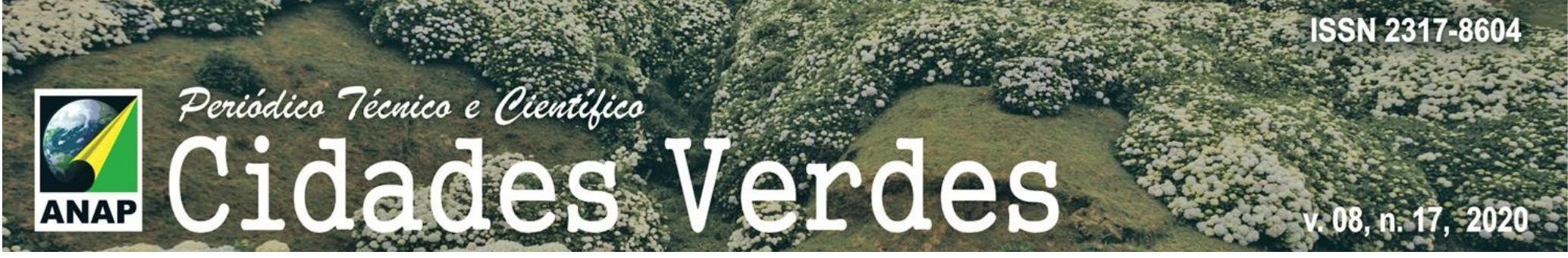

\title{
Resumo
}

Este artigo trata-se de uma sistematização de experiências de Valorização de resíduos orgânicos em Florianópolis, sendo uma pesquisa de abordagem qualitativa, de natureza descritiva, que teve como objetivo compreender o processo de compostagem dos resíduos sólidos orgânicos no município de Florianópolis e sua importância para a população. A pesquisa ocorreu na Comcap (Autarquia de Melhoramentos da Capital), a qual desenvolve programas de compostagem no âmbito do município de Florianópolis. A coleta de dados se deu através de entrevistas semi estruturadas, e os participantes são os funcionários e técnicos responsáveis pelo o desenvolvimento do projeto de compostagem da autarquia Comcap. Tal iniciativa visa dar destinação diferenciada aos resíduos orgânicos gerados pela população, diminuindo o impacto ambiental. São tratados anualmente, aproximadamente 3.437 toneladas de resíduos orgânicos provenientes de restaurantes, de alguns condomínios e de podas e roçadas de áreas públicas, sendo de grande relevância para os munícipes e que torna Florianópolis umas das cidades destaques na valorização de resíduos orgânicos.

Palavras - chave: Comcap; Compostagem; Resíduos orgânicos.

\begin{abstract}
This article is a systematization of experiences of valorization of organic waste in Florianópolis, being a qualitative approach research, descriptive nature, which aimed to understand the process of composting of organic solid waste in the city of Florianópolis and its importance to the population. The research took place at Comcap (Capital Improvement Authority), which develops composting programs in Florianópolis. Data were collected through semi-structured interviews, and the participants are the employees and technicians responsible for the development of the Comcap municipality composting project. This initiative aims to give differentiated destination to organic waste generated by the population, reducing the environmental impact. Approximately 3,437 tons of organic waste from restaurants, some condominiums and public pruning and mowing are treated annually, being of great relevance to the residents and making Florianópolis one of the cities highlights in the valorization of organic waste.
\end{abstract}

Keywords: Comcap; Composting; Organic waste.

\section{Resumen}

Este artículo es una sistematización de experiencias de valorización de residuos orgánicos en Florianópolis, siendo un enfoque de investigación cualitativa, de carácter descriptivo, que tuvo como objetivo comprender el proceso de compostaje de residuos sólidos orgánicos en la ciudad de Florianópolis y su importancia para la población. La investigación tuvo lugar en Comcap (Autoridad de Mejoramiento de Capital), que desarrolla programas de compostaje en Florianópolis. Los datos fueron recolectados a través de entrevistas semiestructuradas, y los participantes son los empleados y técnicos responsables del desarrollo del proyecto de compostaje municipal de Comcap. Esta iniciativa tiene como objetivo dar un destino diferenciado a los desechos orgánicos generados por la población, reduciendo el impacto ambiental. Aproximadamente 3,437 toneladas de desechos orgánicos de restaurantes, algunos condominios y podas públicas y poda se tratan anualmente, siendo de gran relevancia para los residentes y haciendo de Florianópolis uno de los puntos destacados de la ciudad en la valorización de los desechos orgánicos.

Palabras Ilave: Comcap; Compostaje; Residuos orgánicos 


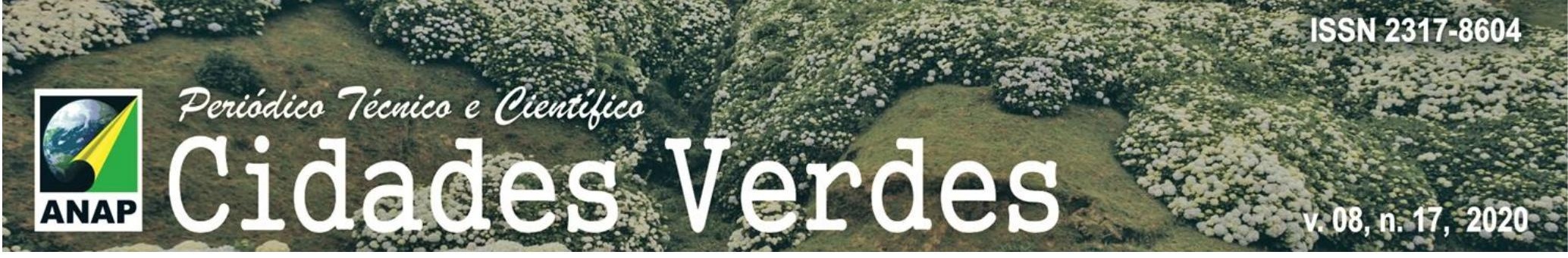

\section{INTRODUÇÃO}

O rápido processo de transformação que vem passando a sociedade atual apresenta grandes consequências ambientais, que nos últimos tempos têm sido foco por parte de todos, sendo governos e sociedade em geral. (CALDERONI, 2003).

A sociedade busca pelo conforto e extrai da natureza os seus recursos naturais, que inúmeras vezes são desperdiçadas posteriormente, ocorrendo uma grande quantidade de resíduos sólidos, e assim causando impactos ambientais. Em países que é mais industrializados, as quantidades de resíduos produzidos são ainda maiores, pois quanto mais rico é o país, mais se desperdiça, o que nos leva a acreditar que a composição e a quantidade de resíduos produzidos estão diretamente relacionadas com o modo de vida das populações (ANDREOLI ET AL 2014).

Na data de 2 de agosto de 2010 foi instituída a Política Nacional de Resíduos Sólidos (PNRS), por meio da Lei n.o 12.305. Sendo um marco histórico da gestão ambiental no Brasil, pois lança uma nova visão na luta contra um dos maiores problemas do planeta: o lixo urbano. A PNRS reúne princípios, objetivos, instrumentos e diretrizes para a gestão dos resíduos sólidos (BRASIL, 2010). Desta forma, os resíduos sólidos são produzidos a partir de atividades de origem doméstica, industrial, comercial hospitalar, agrícola, e podem ser utilizados como matéria-prima, diferentemente de lixo, que pode ser entendido como algo impossível de ser reaproveitado (ANDREOLI ET AL, 2014).

No Brasil, a NBR 10004 (ABNT, 2004) tem apresentado a classificação dos resíduos sólidos de acordo com os riscos potenciais ao meio ambiente, sendo assim os resíduos são classificados em três classes: (a)Resíduos Classe I perigosos: resíduos sólidos ou mistura de resíduos que em função de suas características de inflamabilidade, reatividade, corrosividade, patogenicidade e toxicidade, podem apresentar risco à saúde pública, podendo provocar ou contribuir para o aumento de mortalidade ou incidência de doenças, apresentando efeitos adversos ao meio ambiente, isso quando manuseados ou dispostos de alguma forma inadequada; (b) Resíduos Classe II não inertes ou banais: Esses resíduos podem ter propriedades como biodegradabilidade ou solubilidade em água e combustibilidade. São os resíduos que possuem características do lixo doméstico; (c ) Resíduos Classe III inertes: São aqueles resíduos que não se degradam ou que não se decompõem quando colocados no solo, como resíduos de demolição e construção, rochas e solos provenientes de escavações, vidros e certos plásticos e borrachas que não se decompõe facilmente.

Na classificação dos resíduos sólidos existe uma parcela orgânica e assim para se entender melhor o que é a parcela orgânica, é fundamental entender o tempo de decomposição dos diferentes materiais e produtos, pois o tempo de decomposição da maior parte dos resíduos orgânicos é curto, sendo até um ano, os resíduos inorgânicos levam muitos anos para se decompor, podendo chegar ao extremo como por exemplo, como pneus e garrafas PET, cujo tempo de decomposição é indeterminado (MMA, 2017).

De acordo com o Ministério do Meio Ambiente (2017), os resíduos orgânicos são aqueles constituídos por restos de animais ou vegetais que são descartados, sendo diversas origens, como doméstica ou urbana, como por exemplo, restos de alimentos e podas, agrícola ou industrial, que são resíduos de agroindústria alimentícia, indústria madeireira, frigoríficos e de saneamento básico.

Atualmente no Brasil a destinação dos resíduos orgânicos urbanos é o aterro sanitário. Cerca de 40 milhões de toneladas de resíduos orgânicos são destinados aos aterros como rejeitos (IPEA, 2012). 


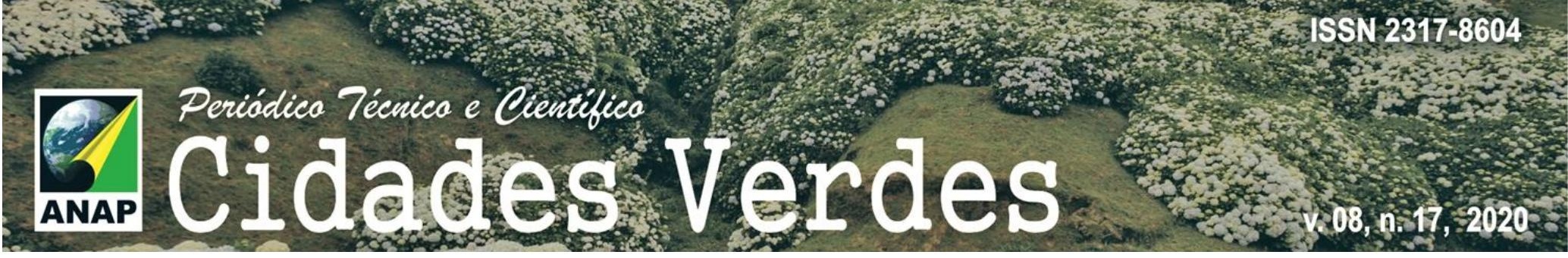

Desta forma uma boa finalidade para essa parcela orgânica é a compostagem, que consiste num processo natural e de fácil realização, sendo uma solução que transforma resíduos orgânicos, como restos de alimentos, de manutenção de áreas verdes e até certa proporção de papéis/papelões em composto, se tornado um fertilizante naturalmente rico em nutrientes e que pode, dentre outras coisas, ser utilizado em jardins e hortas (RICCl, 2017).

A valorização de resíduos orgânicos, significa a facilitação do processo de compostagem a garantia da qualidade do adubo final. E reduz também a contaminação dos resíduos recicláveis secos, como papel, plástico, vidro, metal entre outros. Desta forma, nas centrais de triagem, os catadores separam os tipo de resíduo que pode ser encaminhado para as indústrias que realizam a reciclagem, pois quanto menos resíduo orgânico chegar nas centrais de triagem, mais fácil será a separação dos resíduos secos e também melhores serão as condições de trabalho para esses profissionais (MMA, 2017).

Assim sendo, a valorização dos resíduos, garante retorno positivo ao meio ambiente e à sociedade, porque reduz o impacto ambiental, promove o desenvolvimento econômico das famílias beneficiadas e permite economia aos cofres públicos, devido ao fato em que a municipalidade deixa de pagar pelos serviços de transporte e aterramento (COMCAP, 2017).

De acordo com MPEP (2013) a compostagem é considerada como uma forma eficiente de biodegradação controlada da parcela orgânica dos resíduos sólidos, quando se é comparada aos sistemas atualmente vigentes, como, por exemplo, os aterros sanitários, pois nestes locais não existe o controle do processo de biodegradação da matéria orgânica e por consequência são gerados gases e líquidos, chamado de chorume, que são indesejáveis. Sendo assim, a compostagem é incentivada pela Política Nacional de Resíduos Sólidos.

A compostagem vem sendo definida como um processo aeróbico controlado, que é desenvolvida por uma colônia diversificada de microrganismos, realizada em duas fases distintas: a primeira, é quando ocorre as reações bioquímicas de oxidação, sendo mais intensas e predominantemente termofílicas; a segunda, é conhecida como fase de maturação, é quando ocorre o processo de humificação. (PEREIRA NETO, 1996 apud PEIXE e HACK, 2014). Conforme o autor, o processo de compostagem ocorre de forma natural com a degradação da matéria orgânica. Essa técnica surgiu através da observação do ciclo de vida dos seres, pois sempre se observou que tudo que é vivo, nasce, cresce, morre e se decompõe. Como cita Lavoisier: na natureza nada se cria nada se perde tudo se transforma. Ela pode trazer benefícios ambientais para toda a sociedade, vez que a salvaguarda do meio ambiente interessa a toda a população. Qualquer ação que diminua a pressão sobre os recursos naturais interessa, desta forma, a toda a sociedade. Do ponto de vista das vantagens financeiras, pode significar economia de recursos para dar destino correto a parcela orgânica dos resíduos sólidos, além de gerar produto que poderá ser comercializado, dentre outros aspectos. (BATISTA ET AL, 2016).

A importância da compostagem em nosso cotidiano é buscar uma alternativa para a destinação dos resíduos orgânico, que seja ambientalmente adequada, sendo de baixo custo e que facilmente possa ser assimilada pela população. A obtenção de um composto orgânico de alta qualidade, que sirva como fertilizante orgânico para diferentes objetivos, podendo ser usado para adubar hortas e jardins urbanos, desta forma contribui para a ampliação de áreas verdes, para o aumento da biodiversidade e da segurança alimentar (MMA, 2017).

É importante reciclar os resíduos orgânicos e reestabelecer seu papel natural de fertilizar os solos, e é um grande desafio ambiental que é enfrentado atualmente e somente com envolvimento coletivo 


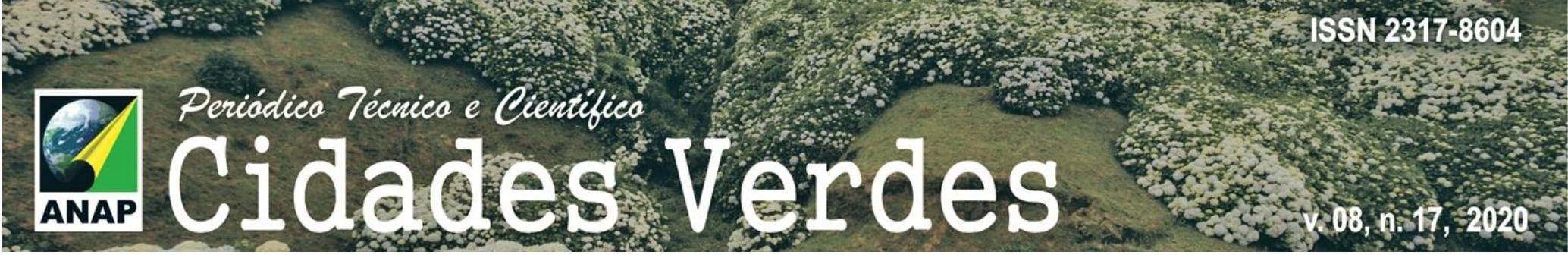

alcançaremos sucesso em uma das muitas frentes para a efetiva implementação da Política Nacional de Resíduos Sólidos (MMA, 2017). De acordo com Ricci (2017) o benefício do composto é a composição rica em matéria orgânica e húmus, sendo uma substância de cor marrom de grande importância para o solo. Ele age impedindo a perda de nutrientes das plantas, absorve a água e evita os processos erosivos decorrentes. A matéria orgânica reduz a compactação do solo, no qual cria pequenos canais para o avanço das raízes, minhocas e outros seres vivos presentes no solo. Atua também como fonte de alimentação para micróbios e invertebrados, que auxiliam na manutenção de um solo com diversidade biológica.

Os compostos gerados podem ser utilizados na agricultura ou na recuperação de áreas degradadas, entre outros .

Atualmente a agricultura sofre com o empobrecimento dos solos agravado pelo uso abusivo de fertilizantes minerais que, por sua vez, necessitam de elevada quantidade de energia para serem produzidos e distribuídos. O Brasil, por exemplo, que é o quarto maior consumidor deste tipo de matéria-prima no mundo (IPEA, 2012).

Conforme destaca Lazzari (2017),

A aplicação de resíduos orgânicos ao solo é utilizada para aumentar os teores de nutrientes disponíveis às plantas e também é uma forma de dar um destino mais adequado aos resíduos das atividades agrícolas e urbanas (p.29).

É importante destacar que nem todos os tipos de resíduos orgânicos podem se tornar composto, pois depende da técnica escolhida, se é compostagem de decomposição aeróbia ou vermicompostagem, e da capacidade de manutenção do processo de tratamento. Sendo assim, a compostagem aeróbia normalmente recicla facilmente grandes quantidades de resíduos provenientes de jardins, áreas verdes e alimentação. O composto a vermicompostagem precisa de quantidades menores e constantes de resíduos de comida para a alimentação das minhocas que participam do processo e pode gerar também fertilizante líquido (RICCl, 2017).

A maioria da população não tem conhecimento da compostagem ou de como fazê-la, além de informações incorretas que contribuem para que a mesma não seja realizada. Dentre os principais argumentos apontados para que o processo de compostagem seja desconsiderado estão o imaginário de que o mesmo demanda muitos materiais, tempo de trabalho e um espaço especial (BRASIL 2013). De Acordo com Batista et al (2016) mesmo com a consciência dos benefícios da compostagem, a sua aplicação na prática pode parecer difícil para quem não tem costume, sendo necessário o conhecimento da técnica.

São coletados, no município, aproximadamente 209.318 mil toneladas/ano de resíduos sólidos (COMCAP, 2018), volume que aumenta a cada ano. O projeto de compostagem surgiu como uma alternativa, possibilitando a valorização da parte da parcela orgânica dos resíduos sólidos orgânicos coletados (destaque-se que ainda é uma pequena parte do resíduo total coletado que é compostado). Afinal, não é possível pensar coleta seletiva apenas nos resíduos secos (plástico, papéis e metal). Dessa forma o método leiras estáticas com aeração passiva (conhecido como método UFSC - Universidade Federal de Santa Catarina), foi implementado em Florianópolis pela prefeitura municipal, através da Autarquia de Melhoramentos da Capital (Comcap). Nesse sentido, a pesquisa na Comcap possibilitou 


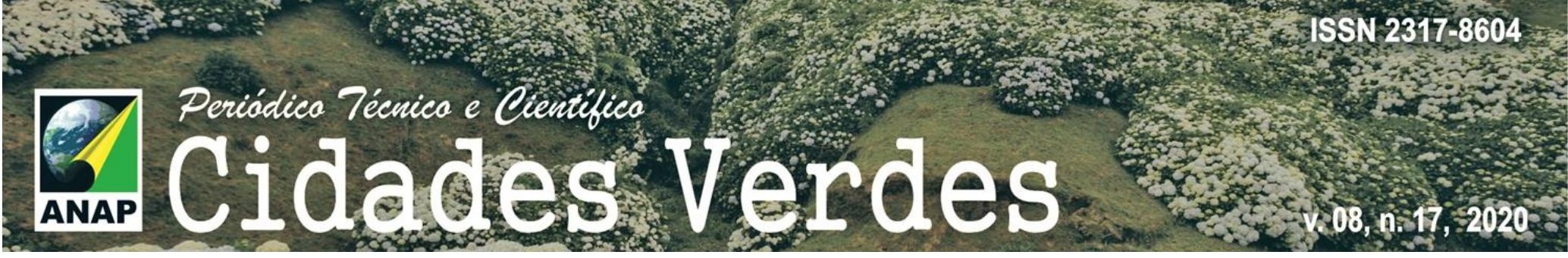

compreender todo o processo que vem sendo realizado sobre a coleta dos resíduos sólidos, a realização da separação dos resíduos orgânicos e realização da compostagem destes, além de permitir identificar a importância que tal iniciativa representa ao meio ambiente e a toda população atendida da ilha.

\section{OBJETIVOS}

O objetivo geral consiste em: Realizar sistematização de experiência, buscando conhecer melhor atividades que são desenvolvidas em Florianópolis, referência na gestão e valorização de resíduos sólidos orgânicos.

Os objetivos específicos consistem em: Compreender o processo de compostagem dos resíduos sólidos orgânicos no município de Florianópolis; entender a importância da compostagem dos resíduos sólidos para a população e para o meio ambiente.

\section{METODOLOGIA}

A presente pesquisa é um estudo de abordagem qualitativa, de natureza descritiva, pois tem como objetivo retratar determinada população ou fenômeno e exploratória, já que proporciona visão geral, de tipo aproximativo (GIL, 2009). A técnica para obtenção dos dados consistiu em entrevista semidirigida, adequadas para estudos exploratórios (LAKATOS; MARCONI, 2011) e observação simples, sendo focada ao conhecimento de situações que possuem certo caráter público (GIL, 2009). Os participantes da pesquisa são funcionários e técnicos responsáveis pelo o desenvolvimento do projeto de compostagem da autarquia Comcap no município de Florianópolis que, desde do ano de 2008, possui pátio de compostagem no Centro de Valorização de Resíduos (CVR) do Itacorubi, Florianópolis, em parceria com a Associação Orgânica e Universidade Federal de Santa Catarina.

\section{RESULTADOS}

A Comcap no ano de 2018 realizou a coleta de 209.318 toneladas de resíduos sólidos, destes $35 \%$ são resíduos orgânicos, ou seja, sendo 73.261,20 toneladas e, através de seu programa de compostagem tem desviado do Aterro Sanitário aproximadamente $4,69 \%$ de todo dos resíduos orgânicos e tem como meta desviar em torno de $25 \%$. Se consolidando assim, como importante ator no processo de valorização dos resíduos orgânicos municipais. E Suas ações vão além do pátio propriamente dito (CVR), pois desenvolvem, a partir dele, importantes programas de educação ambiental com diferentes públicos.

É importante evidenciarmos que Comcap fortalece e disponibiliza recursos para os pátios comunitários de compostagem como a "Revolução dos Baldinhos" e "Pacuca", que são referência no tratamento comunitário de resíduos orgânicos, e atualmente visam criar mais 5 pátios de compostagem, e para a alimentação destes será realizado uma coleta exclusiva de resíduos orgânicos através de PEVs (pontos de entrega voluntária). Isso proporciona a valorização e economia para o município, pois reduz a coleta e o transporte dos resíduos até o Aterro sanitário. 


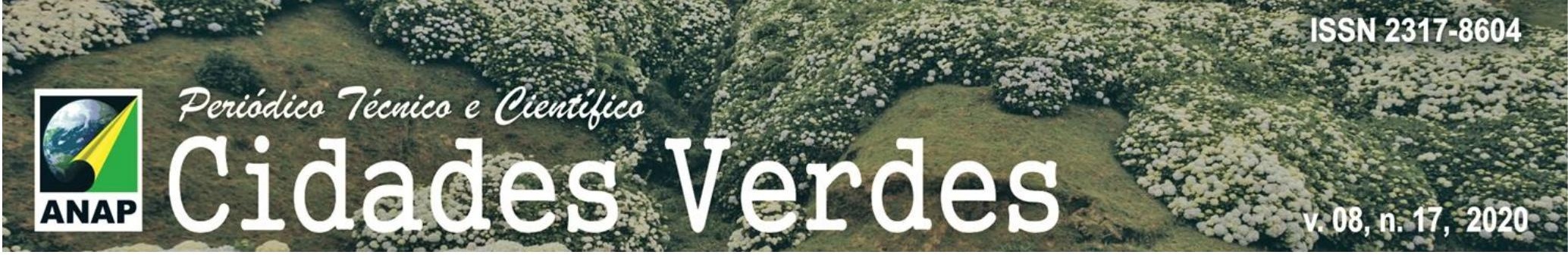

Através da doação de minhocários e capacitação que busca atender a demanda de cidadãos dispostos a tratar seus resíduos orgânicos no âmbito domiciliar e comunitário, realiza diversas campanhas de conscientização e incentivo para que as pessoas (incluindo organizações comunitárias formais ou informais) participem dos projetos disponibilizados. Logo, o volume total dos resíduos compostados em Florianópolis é bastante superior àquele dado oficial atualmente.

A compostagem realizada dentro do pátio próprio situado no CVR conta com a parceria de vários restaurantes da cidade, os quais separam e disponibilizam seus resíduos orgânicos. Estes resíduos, somados as "galhadas" de árvores que são coletadas e passam no processo de trituração, são utilizadas no processo da montagem da composteira. $O$ composto final é utilizado pela gestão pública na manutenção de praças e jardins e também disponibilizados para projetos de agricultura urbana, sendo mais de 100 hortas urbanas atendidas. Sendo assim o projeto propõe diferentes iniciativas, contribuindo com as tecnologias sociais, devido às peculiaridades e características de cada comunidade beneficiada.

Desta forma, Florianópolis se destaca com a Lei municipal $n^{\circ} 10.501$, de 08 de abril de 2019, que dispõe sobre a obrigatoriedade da reciclagem de resíduos sólidos orgânicos no município, que contribui estimulando as iniciativas comunitárias e de cooperativas e incentivando a compostagem doméstica e viabilizando sistemas de coleta domiciliar dos resíduos sólidos orgânicos, preferencialmente por meio da gestão comunitária (BRASIL, 2019) contribuindo ainda mais com as iniciativas e a conscientização que são realizadas pela Comcap.

Sendo assim, o município de Florianópolis pretende ter Lixo Zero até o ano de 2030, ou seja, mais de 100 mil toneladas deixarão de ir para o aterro sanitário anualmente, com a ajuda dos munícipes.

\section{CONCLUSÃO}

O crescimento populacional no município de Florianópolis vem se mostrando intenso nos últimos anos. Concomitante a isso, os resíduos sólidos também aumentaram. Nesse sentido, o projeto realizado pela Comcap veio como uma forma de diminuir os impactos ambientais e econômicos que isso acarreta ao município e a população. Ao implementar atividades que visam a compostagem de resíduos orgânicos sendo mais de 73 mil toneladas recolhidas por ano pela coleta convencional é possível dar um destino diferenciado e correto a esses resíduos, desviando-os do aterro sanitário. Além disso a proposta atua em três frentes de tratamento de resíduos: compostagem domiciliar, compostagem comunitária e compostagem em grandes pátios, focando em diferentes públicos. Tudo isso possibilita maior funcionamento das atividades, que são de extrema importância para a população, sobretudo no que tange às questões ambientais.

A sistematização desta experiência foi a etapa inicial para a realização do projeto de compostagem na moradia estudantil na Universidade Federal de Santa Catarina, e que prevê implantação também em outras cidades no estado de Santa Catarina em 2019, estimulando que outras cidades como Florianópolis se preocupem e realizem a valorização dos resíduos sólidos orgânicos em seus municípios.

Portanto, é fundamental que se realizem novas pesquisas com relação a compostagem de resíduos sólidos orgânicos tanto no município de Florianópolis como no âmbito nacional, devido a sua importância e benefícios para todo a sociedade. 


\section{REFERÊNCIAS BIBLIOGRÁFICAS}

ASSOCIAÇÃO BRASILEIRA DE NORMAS TÉCNICAS - ABNT. NBR 10.004/2004: Resíduos Sólidos - Classificação. 2a ed. Rio de Janeiro, 2004.

ALVES, Vicente Rosa. A Efetividade na Gestão do Meio Ambiente: 0 caso do município de Florianópolis Dissertação de Mestrado. Universidade Federal de Santa Catarina - Florianópolis, 1995.

ANDREOLI, C. V. ET AL. Resíduos sólidos origem, classificação e solução para destinação final adequada. 2004. Disponível: https://www.agrinho.com.br/site/wp-content/uploads/2014/09/32_Residuos-solidos.pdf. Acesso em: 08 de outubro de 2018.

BATISTA, C.C.N; ET AL. Compostagem doméstica: desafios e possibilidades ao gerenciamento de resíduos orgânicos do lar. Rev. Educação Ambiental em Ação. ISSN 1678-0701, Número 58, Ano XV. Dezembro2016/Fevereiro-2017N 1678-0701. 2016

BRASIL, Florianópolis. Leis municipais. Florianópolis. 2019. Disponivel: https://leismunicipais.com.br/a/sc/f/florianopolis/lei-ordinaria/2019/1051/10501/lei-ordinaria-n-10501-2019dispoe-sobre-a-obrigatoriedade-da-reciclagem-de-residuos-solidos-organicos-no-municipio-de-florianopolis. Acesso em: 20 de maio de 2019.

CALDERONI, S. Os bilhões perdidos no lixo. 4. ed. São Paulo: Humanitas editora,. 2003. Compromisso Empresarial para Reciclagem (CEMPRE) - Política Nacional de Resíduos Sólidos - Agora é lei: Novos desafios para poder público, empresas, catadores e população. Disponível em .

COMPANHIA DE MELHORAMENTOS DA CAPITAL (Florianópolis). Indicações da Geração de Resíduos. 2017. Disponível em:

<http://www.pmf.sc.gov.br/entidades/comcap/index.php?cms=indicadores+da+geracao+de+residuos\&menu= 5\&submenuid=1414>. Acesso em: 07 dez. 2018.

COMPANHIA DE MELHORAMENTOS DA CAPITAL (Florianópolis). Movimentação de resíduos em 2018 Departamento de Coleta de Resíduos Sólidos Comcap. Disponível em:

<http://www.pmf.sc.gov.br/entidades/comcap/index.php?cms=valorizacao+de+residuos+solidos\&menu=6\&su bmenuid=1414>. Acesso em: 27 maio 2019.

GIL, A., C. Métodos e técnicas de pesquisa social. São Paulo: Atlas 6 Ed.2009.

LAKATOS, E. M.; MARCONI, M. de A. Fundamentos de Metodologia Científica. 5. ed. São Paulo: Atlas, 2003.

IPEA. Diagnóstico dos Resíduos Orgânicos do Setor Agrossilvopastoril e Agroindústrias Associadas. 2012. Disponível:

http://www.ipea.gov.br/agencia/images/stories/PDFs/relatoriopesquisa/120917_relatorio_residuos_organico s.pdf. Acesso em: 07 de outubro de 2018.

LAKATOS, E. M.; MARCONI, M. A. Metodologia científica. 6. ed. São Paulo: Atlas, 2011.

LAZZARI, Cleiton Júnior Ribeiro. Atributos químicos e frações de fósforo em solos de áreas de compostagem no município de Florianópolis-SC. 2017. Dissertação (Mestrado) - Universidade Federal de Santa Catarina, Centro de Ciências Agrárias, Programa de Pós-Graduação em Agroecossistemas, Florianópolis, 2017. Disponível em: http://www.bu.ufsc.br/teses/PAGR0390-D.pdf

MINISTÉRIO DO MEIO AMBIENTE. Gestão de Resíduos Orgânicos. 2017. Disponivel: https://www.mma.gov.br/cidades-sustentaveis/residuos-solidos/gest\%C3\%A3o-de-res\%C3\%ADduosorg\%C3\%A2nicos.html. Acesso em: 08 de outubro de 2018.

MINISTÉRIO PÚBLICO DO ESTADO DO PARANÁ. Unidades de Triagem e Compostagem de Resíduos Sólidos Urbanos. 2013. 2a

Edição.Curitiba.Disponivel:http://www.meioambiente.mppr.mp.br/arquivos/File/Apostila_compostagem_Fina I_Pos_Print.pdf. Acesso: 20 de agosto de 2018. 


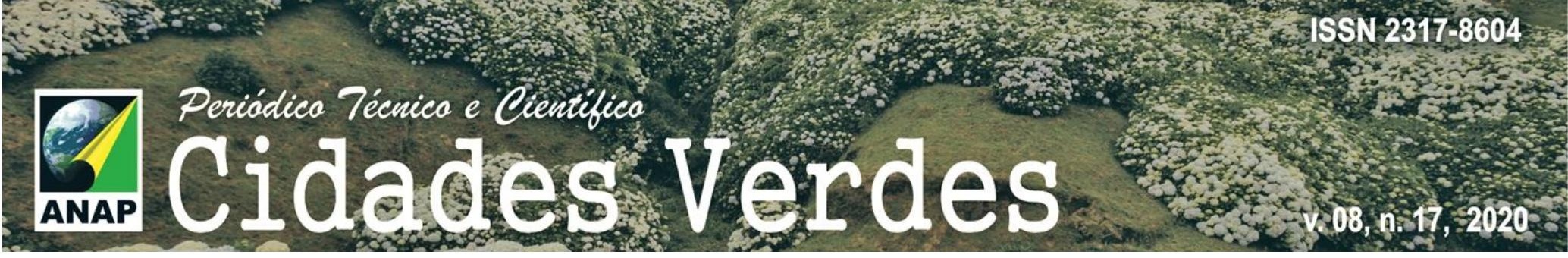

PEIXE, Marildo; BROGNOLI HACK, Mara. Compostagem como método adequado ao tratamento dos resíduos sólidos orgânicos urbanos. Experiência do Município de Florianópolis/SC, 2014.

RICCI, M. Manual para gestão de resíduos orgânicos nas escolas. Climate and Clean Air Coalition/Municipal Solid Waste Initiative (CCAC MSWI). São Paulo, 2017. Disponível em:

http://www.ccacoalition.org/sites/default/files/2016_A-Handbook-for-schools-on-organic-wastemanagement_ISWA_CCAC_Portuguese.pdf. Acesso em: 08 de outubro de 2018.

ZAMBON, Matheus M., LUNA, MÔNICA M. M. Resíduos Orgânicos Urbanos: Um Olhar sobre Florianópolis Encontro Internacional sobre gestão Empresarial e Meio Ambiente, 2016. 